\title{
The effect of viewing geometry and wavelength on the relationship between reflectance and suspended sediment concentration
}

\author{
E. M. M. NOVO \\ Instituto de Pesquisas Espaciais, Caixa Postal 515, \\ 12200, Sao Jose dos Campos, Sao Paulo, Brazil \\ and J. D. HANSOM and P. J. CURRAN \\ Department of Geography, University of Shefficld, Western Bank, \\ Sheffield S10 2TN. England
}

(Received 28 September 1987: in final form 15 June 1988)

\begin{abstract}
The relationship between reflectance and suspended sediment conentration (SSC) is dependent upon the wavebands sensed and the viewing geometry of the sensor. The laboratory experiment reported in this paper investigated these dependences. The retlectance in four wavebands (two visible and two near-infrared) of a large water-filled and wave-free tank were recorded as three variables were changed, nanely SSC, sensor viewing angle and relative sensor azimuth. The strength of the positive relationship between reflectance and SSC was shown to vary with (i) wavelength, as the maximum reflectance and SSC class separability occurred at the longer visible wavelengths, and (ii) viewing geometry, as the reflectance/SSC asymptote was dependent upon both the angle and azimuth of the sensor. The optimum conditions for the sensing of SSC were concluded to be nadir in visible $(0.55$ and $0.65 \mu \mathrm{m})$ and near-infrared $(0.75 \mu \mathrm{m})$ wavelengths.
\end{abstract}

\section{Introduction}

Most objects on the Earth's surface are non-Lambertian (Slater 1980) with reflectance being dependent upon both the direction of irradiating energy and the direction along which reflected energy is detccted (Ranson et al. 1985). In recent years much work has been undertaken on these bidirectional reflectance properties for regetation surfaces (Kriebel 1978, Kimes et al. 1980, Koilenkank et al. 1982, Wardley 1984. Ranson et al. 1985, Milton and Webb 1987). Although the bidirectional reflectance properties of water are well documented (Jerlov 1976, Preisendorfer 1976, Coney and Salzman 1979, Alfoldi 1982, MacFarlane and Robinson 1984) the specific influence of viewing geometry on the relationship between remotely-sensed reflectance and suspended sediment concentration (SSC) has received scant attention (Curran and Novo 1988). This can be attributed to the problems of performing experiments in the field where water properties are in constant flux or in the laboratory where it is difficult to simulate the multiple scattering that occurs within an unbounded water body (McCluney 1976). Despite these problems, detailed laboratory studies have provided useful results (Scherz et al. 1969, Scherz 1972, Moore 1977, Whitlock et al. 1982) that complement the necessarily less detailed field studies (Bartolucci et al. 1977, Holyer 1978). For instance, such laboratory studies have clearly demonstrated positive but asymptotic relationships between SSC and reflectance: the influence of bottom reflectance when SSC is less than $10 \mathrm{mg} / \mathrm{l}$ and the 
long wavelength shift in the start of the reflectance asymptote at high levels of SSC. Building upon this information several workers have developed empirical models with which to estimate SSC from remotely-sensed measurements of reflectance (McCauley and Yarger 1976, Ritchie et al. 1976, Khorram 1981, Curran et al. 1987. Rimmer et al. 1987). Such models have been applied under a wide range of suboptimal conditions including a fixed viewing geometry, no atmospheric correction and high levels of SSC. As a result the accuracy with which remotely-sensed measurements have been used to estimate SSC has been low (Curran et al. 1987).

The objective of the research reported here was to use a laboratory study to evaluate the influence of viewing geometry on the relationship between SSC and reflectance, an evaluation which is essential if remotely-sensed reflectance is to be employed to estimate accurately the SSC of natural waters.

\section{Remotely-sensed reflectance of water}

\subsection{The effect of SSC on reflectance}

Irradiance on a water surface comprises direct and diffuse solar radiation (figure 1). both of which are partially reflected from the water surface. Any remaining radiation is transmitted via the water surface to be absorbed or scattered by water molecules, particles and suspended sediments. In shallow water, transmitted radiation can be backscattered partially by bottom material, partially absorbed within the water mass and partially internally reflected at the surface. In deep water, transmitted

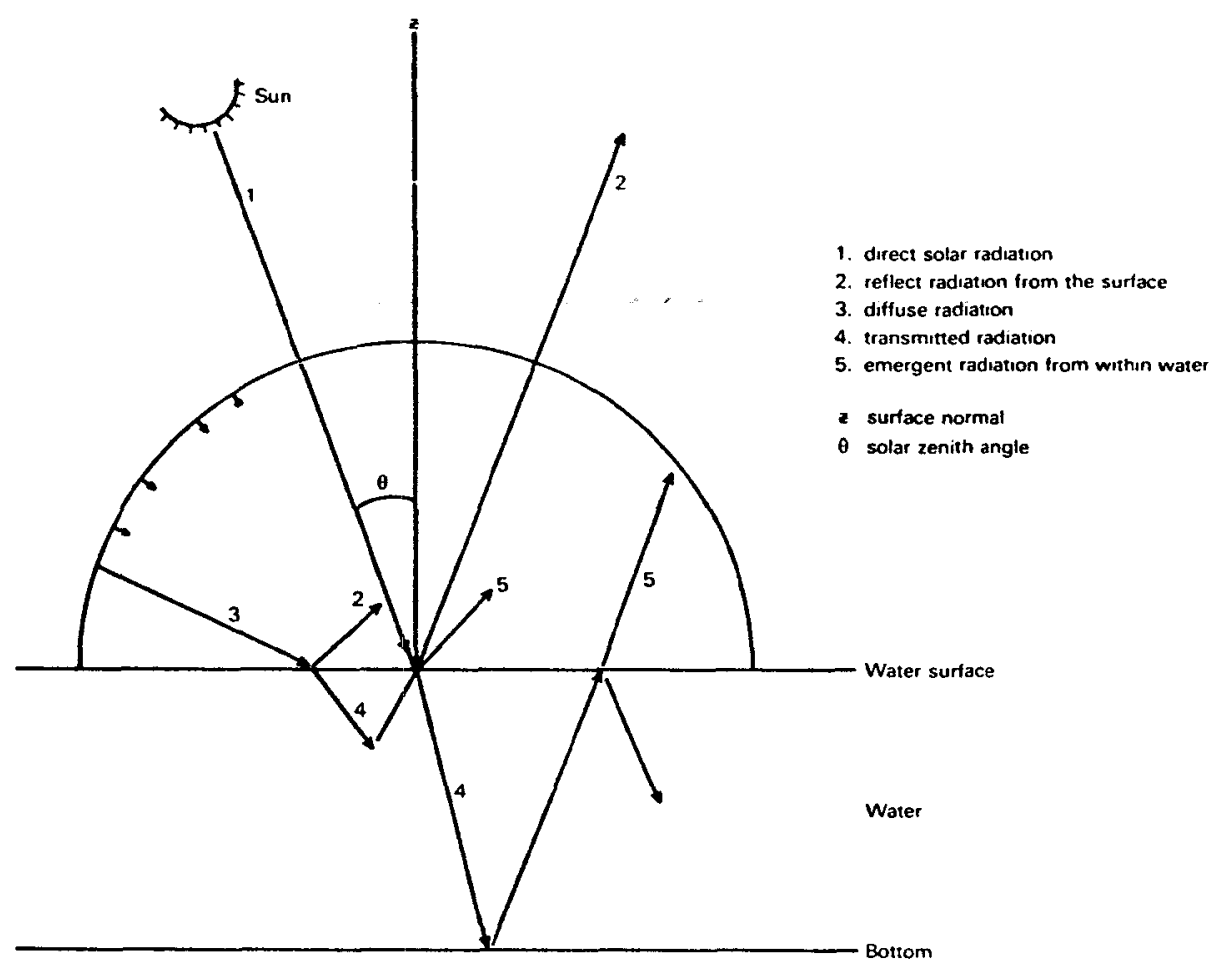

Figure 1. Optical processes in the remote sensing of SSC. 
radiation can be absorbed or backscattered by successive water laminae. Backscattered light from the water body contributes to the reflectance from the water body. its various components and the bottom material. Of these, only the water body or sub-surface reflectance will be affected by SSC as it represents the backscattered radiation from within the water body itself (Holyer 1978). However, the relative proportion of sub-surface and water surface (Fresnell) reflectance detected by the sensor as total reflectance (hereon called reflectance) will vary according to the viewing geometry.

\subsection{The effect of viewing geometry on reflectance}

Both theory and experiment indicate that water reflectance is partly a function of the solar zenith angle (Jerlov 1976, Preisendorfer 1976). Variations in solar zenith angle $\left(\theta_{2}\right)$ during data acquisition have produced changes in reflectance that are unrelated to water properties (figure 2): for example, a 9 per cent increase in reflectance as $\theta_{z}$ increased from $0^{\circ}$ to $70^{\circ}$ has been reported by Jerlov (1976). In addition, as SSC is increased, there is a corresponding increase in the amount of forward scatter. Water bodies with high SSC are therefore subject to variations in reflectance with changes in sensor viewing angle $\left(\theta_{v}\right)$. Further variations in the relative azimuth angle $(\psi)$ will influence the effect that $\theta_{v}$ has on reflectance. For example, when $\psi=0^{\circ}$, variation in $\theta_{v}$ will cause only minor changes in reflectance since the Sun and sensor are in the same plane whereas when $\psi=90^{\circ}$, variations in $\theta_{v}$ into and away from the Sun will cause large changes in reflectance. To minimize the Sun glitter detected with the sensor looking towards the Sun, Clarke and Ewing (1974) recommend that radiance is measured vertically or at predetermined angles away from the Sun. In many remote sensing situations, it may not always be possible to adhere to these recommendations and in such cases a reliable method of assessing changes in the reflectance of water as a function of viewing geometry is essential.

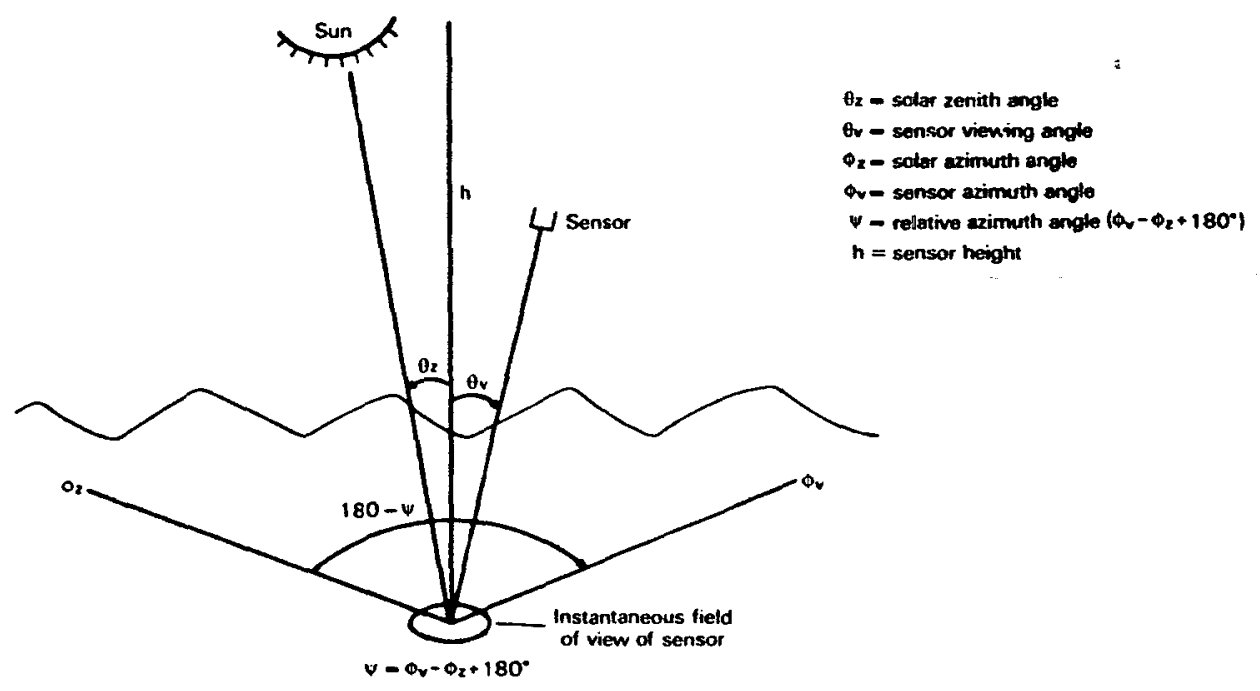

Figure 2. Viewing geometry parameters. 
2.3. The effect of varying SSC and viewing geometries on reflectance

The specific aims of this paper are to establish, under laboratory conditions. the following interrelationships between SSC, viewing geometry and reflectance in both visible and near-infrared wavelengths.

(a) Water reflectance increases with increasing SSC although the sensitivity of the relationship is affected by viewing geometry.

(b) Sensor look directions affect the recorded reflectance with decreasing reflectance away from nadir at high SSC's and small increases in reflectance away from nadir at low SSC"s.

(c) The effect of viewing geometry on the SSC/reflectance relationship is wavelength-dependent.

\section{Experimental method}

The method comprised three components, (a) the variation of SSC. (b) the measurement of each SSC at different viewing geometries and $(c)$ the variation of viewing geometry.

Variation of SSC was achieved using a glass tank $(75 \mathrm{~cm}$ long, $42 \mathrm{~cm}$ wide and $56 \mathrm{~cm}$ deep) whose base was lined with dark material to minimize bottom effects (McCluney 1976) and whose walls were covered with aluminium foil (Scherz et al. 1969) to simulate the effect of multiple scattering. The tank was filled with approximately 3001 of tap water into which increasing amounts of pre-weighed, powdered china clay (kaolin) were mixed. China clay was chosen to simulate, albeit crudely, a clay sediment with a grain size distribution of $1-20 \mu \mathrm{m}$. To derive the $\mathrm{SSC} /$ reflectance relationship, $14 \mathrm{SSCs}$ ranging from $0.0 \mathrm{mg} / 1$ to $1050 \mathrm{mg} / \mathrm{l}$ were used.

A Milton multiband radiometer (Milton 1980) was employed in the measurement of water reflectance in four spectral bands; band 1 centred at $0.55 \mu \mathrm{m}$, band 2 centred at $0.65 \mu \mathrm{m}$, band 3 centred at $0.75 \mu \mathrm{m}$ and band 4 centred at $0.87 \mu \mathrm{m}$. Although theory supports the use of the red band for SSC estimation in the field, spectroradiometric data collected in the laboratory using an infrared intelligent spectroradiometer (IRIS) demonstrated that for all four bands sensed by the Milton multiband radiometer SSC was positively related to reflectance (figure 3 ). Reflectance data were derived from near-sequential measurements of relative radiance from the target and a calibrated reference panel for each SSC and viewing geometry.

Simulation of viewing geometry involved establishing the sensor's field of view (FOV), assessing the area 'seen' by the sensor at different heights and look angles and definition of the viewing geometries to be tested. The effective FOV of the sensor was determined by measuring changes in ground reflectance as a white card was progressively moved away from a nadir position beneath the sensor. Sensor response against card distance away from normal identified the area contributing to the signal. For the $27^{\circ} \mathrm{FOV}$ of the sensor and at a height of $100 \mathrm{~cm}$ this was $0 \cdot 180 \mathrm{~m}^{2} .0 \cdot 186 \mathrm{~m}^{2}$. $0.220 \mathrm{~m}^{2}$ and $0.285 \mathrm{~m}^{2}$ for $\theta_{\mathrm{v}} \mathrm{s}$ of $0^{\circ}, 10^{\circ}, 20^{\circ}$ and $30^{\circ}$ respectively. As the effective tank area was only $0.315 \mathrm{~m}^{2}$, the sensor height was fixed at $50 \mathrm{~cm}$ to ensure a large gap between the area sensed and any possible side effects.

Two off-nadir look directions were used; negative viewing angles to represent looking away from the Sun and positive angles to represent looking towards the Sun (figure 4). The table summarizes the viewing geometries used in the experiment. No 


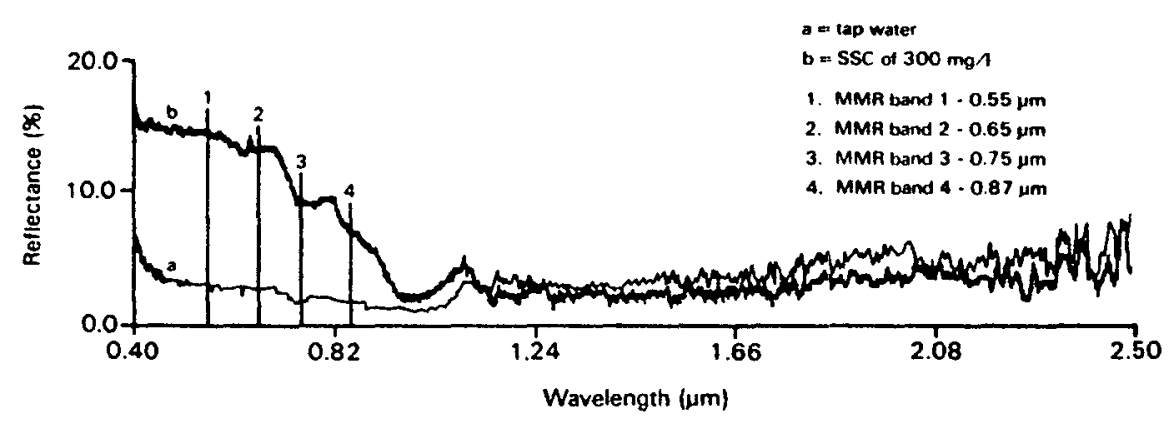

Figure 3. Percentage water reflectance as a function of SSC.

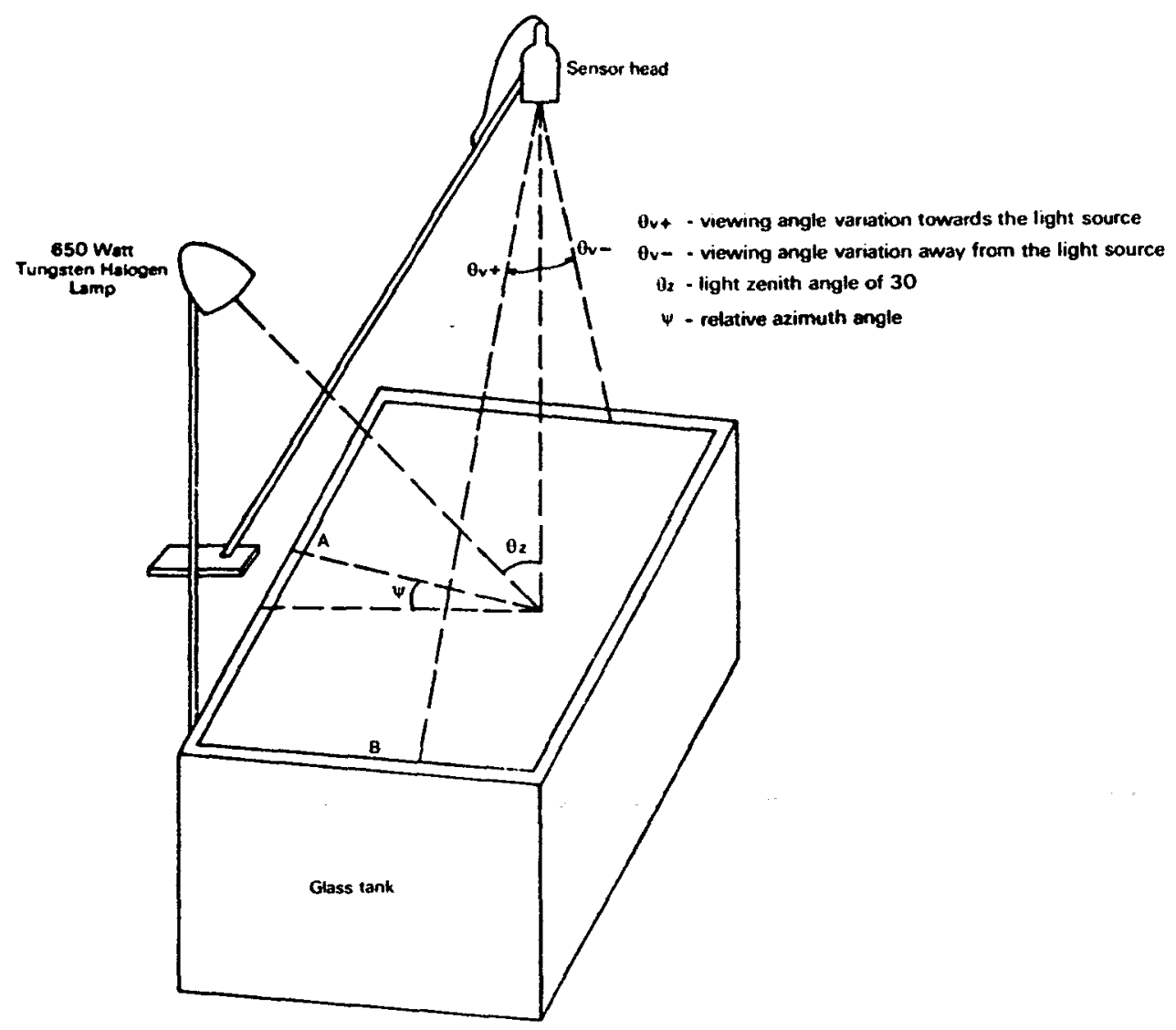

Figure 4. Experimental set up. The labelled items are: (A) lamp position for azimuth angle of $0^{\circ}$, (B) lamp position for izimuth angle of $90^{\circ}$. 
attempt was made to simulate real surface geometry in the form of waves and a stilled water surface was used throughout.

The light source used to simulate the Sun was a $650 \mathrm{~W}$ tungsten-halogen lamp. This provided a most suitable stable, directional and controllable source of broadband illumination.

\section{Results and analysis}

4.1. Effects of viewing geometry on the sensitivity of reflectance to SSC changes

Whilst reflectance increased with increasing SSC at low concentrations, the relationship tended to become asymptotic at higher concentrations in all viewing geometries, with the upper asymptote being reached at different SSC's when viewed under different geometries (figure 5). Variation in the relative azimuth angle $(\psi)$ changed the point at which reflectance reached the asymptote under a constant viewing angle. At nadir viewing, reflectance reached the asymptote at a higher SSC when $\psi=0$. However, when $\psi=90^{\circ}$, reflectance responded more sharply to low SSC variation. For most SSCs, the reflectance was higher when $\psi=90^{\circ}$ than when $\psi=0^{\circ}$.

Variation in the sensor view angle $\left(\theta_{v}\right)$ changed the point where reflectance reached the asymptote for both $\psi$ angles. Positive and negative $\theta_{v}$ increases caused a fall in the sensitivity of reflectance to SSC changes, which was sharper when $\psi=90^{\circ}$ than when $\psi=0^{\circ}$. Overall the message of figure 5 is that the reflectarice, SSC relationship is sensitive to viewing geometry, especially at low SSC.

\subsection{Effects of viewing geometry on the reflectance/SSC relationship in different wavelengths}

A consistent trend of increasing relectance with increasing SSC in the visible (green and red) wavelengths was observed when reflectance was plotted against wavelength for two values of $\psi$ (figure 6). However, such a clear trend did not emerge in near-infrared wavelengths centred at $0.75 \mu \mathrm{m}$ and $0.87 \mu \mathrm{m}$, as reflectance was almost invariant with SSC due to absorption of radiation by water. In visible wavelengths $\psi$ affected the overall levels of reflectance but it did not affect the increasing trend itself. In addition, at SSCs greater than $350 \mathrm{mg} / \mathrm{l}$, the maximum reflectance shifted from band 1 (green) and band 2 (red) independently of $\psi$ (figure 6 ). This shift in maximum reflectance towards longer wavelengths with increasing SSC (Moore 1977) is depicted in diagrammatic form in the figure 6 inset.

The effect of sensor viewing angle $\left(\theta_{v}\right)$ on the reflectance/SSC relationship can be examined in figure 7 when $\psi=0^{\circ}$. In this case positive increases in $\theta_{v}$ decreased the

Viewing geometries used.

\begin{tabular}{cccc}
\hline $\begin{array}{c}\text { Relative } \\
\text { azimuth }(\psi) \\
\left({ }^{\circ}\right)\end{array}$ & $\begin{array}{c}\text { Sensor viewing } \\
\text { angle }\left(0_{\mathrm{v}}\right) \\
\left({ }^{\circ}\right)\end{array}$ & $\begin{array}{c}\text { Relative } \\
\text { azimuth }(\psi) \\
\left({ }^{\circ}\right)\end{array}$ & $\begin{array}{c}\text { Sensor viewing } \\
\text { angle }(0) \\
(())\end{array}$ \\
\hline 0 & 0 & 90 & 0 \\
0 & +10 & 90 & +10 \\
0 & +20 & 90 & +20 \\
0 & +30 & 90 & +30 \\
0 & -10 & 90 & -10 \\
0 & -20 & 90 & -20 \\
0 & -30 & 90 & -30 \\
\hline
\end{tabular}



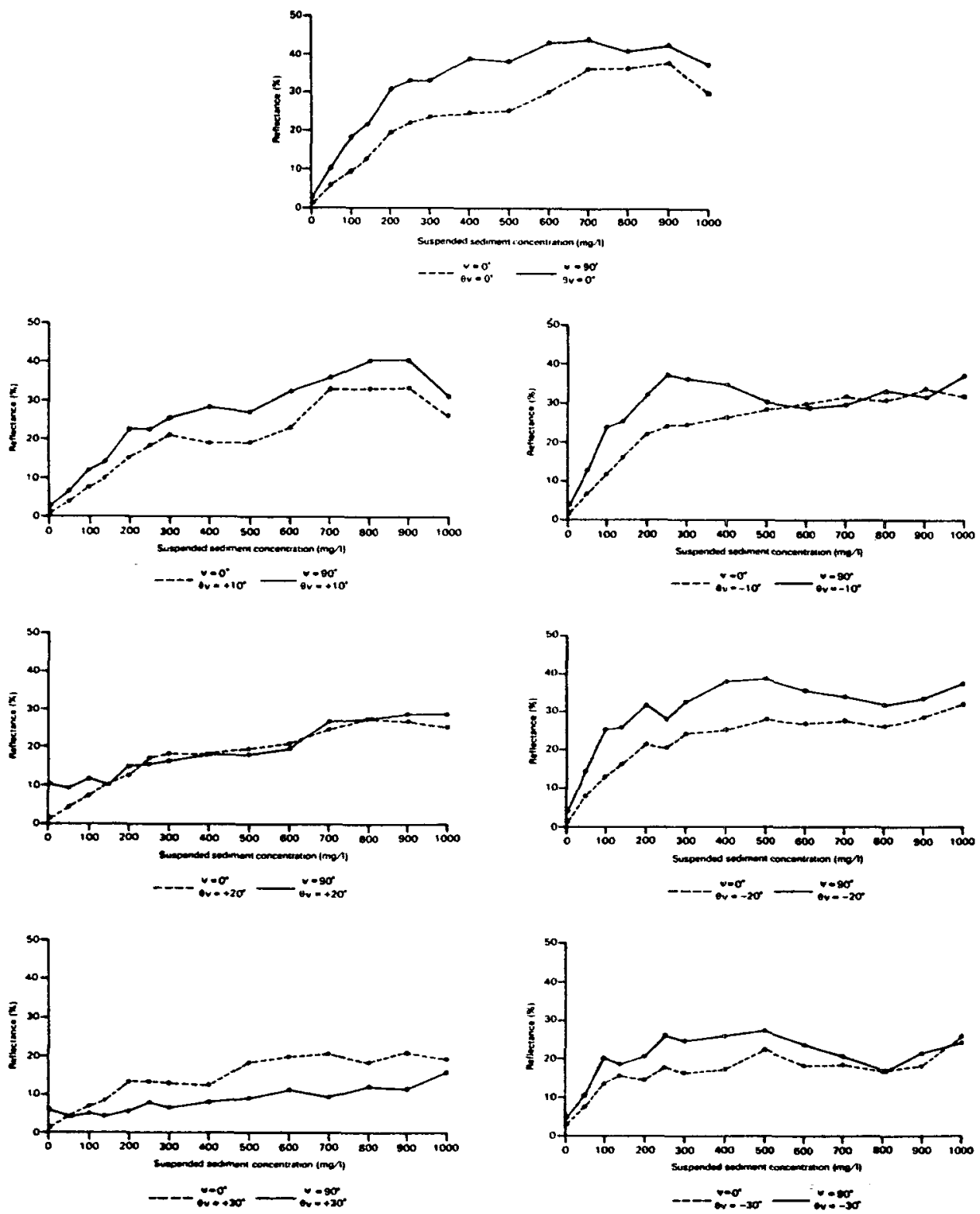

Figure S. Reflectance and SSC at different viewing geometries (green band).

separability between SSC classes in the visible bands but maintained the reflectance shift towards longer wavelengths. Negative increases in $0_{v}$ also produced decreases in SSC class separability but did not always maintain the shift towards longer wavelengths. When $\psi=90^{\circ}$, similar trends were seen although the main difference was that the strength of the reflectance/SSC relationship decreased more rapidly when $\theta_{v}$ was increased. 

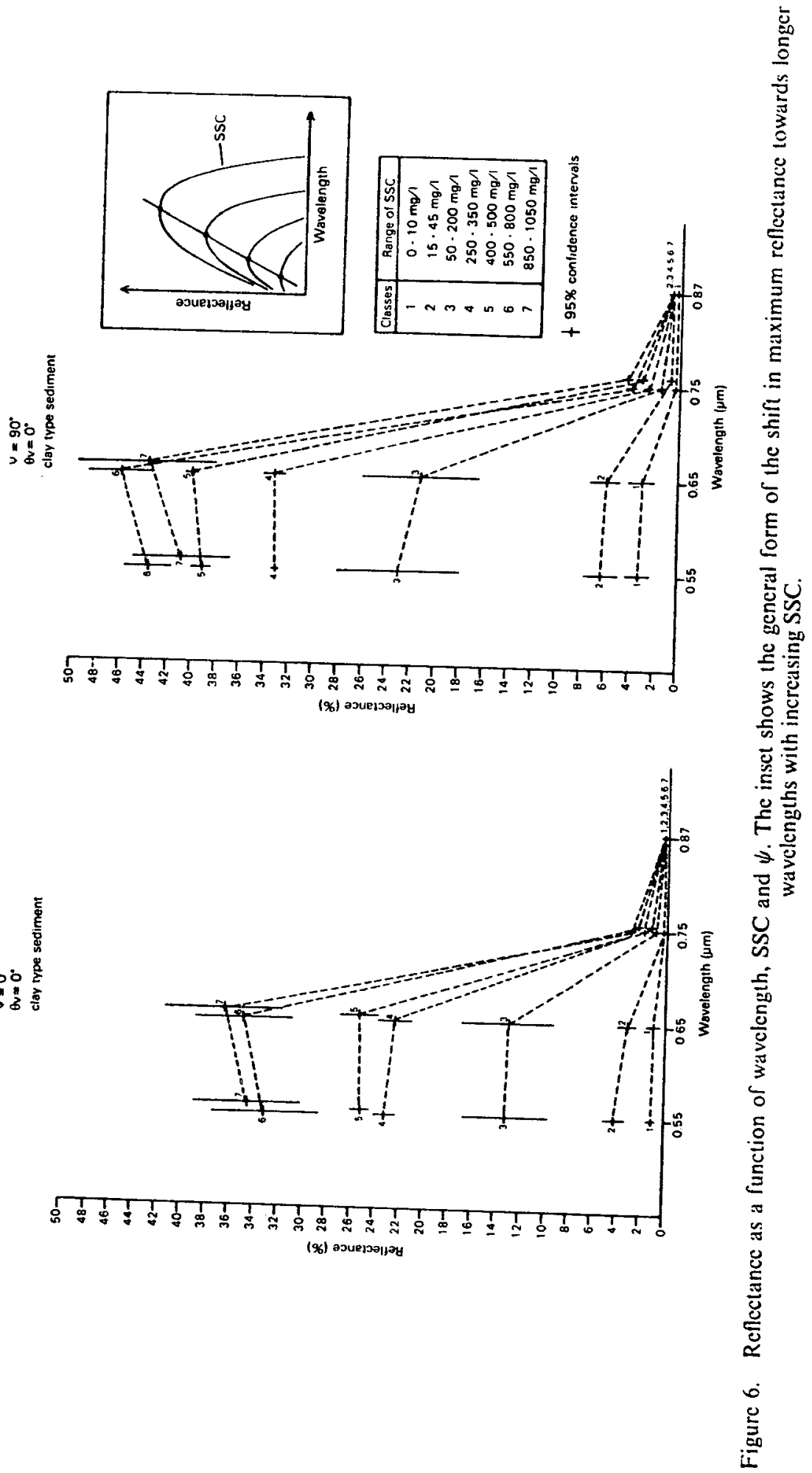
Figures 6 and 7 illustrate that the effect of viewing geometry on the reflectance/SSC relationship was wavelength-dependent, with shifts in maximum reflectance towards longer wavelengths in the visible region as SSC increased.

\subsection{Effects of look direction on the reflectance/SSC relationship}

Variation of reflectance as a function of viewing geometry for the seven classes of SSC showed the effect of $\psi$ and $\theta_{v}$ on reflectance to be dependent on SSC (figure 8). In the visible wavelengths, maximum reflectance shifted towards low negative $\theta_{v}$ as SSC increased, except for the highest SSC classes in the green band $(0.55 \mu \mathrm{m})$ where this trend did not occur. At high SSCs, the forward scattering of light by the particles was increased (Preisendorfer 1976) and at $\theta_{v}=+30^{\circ}$ this increase in scattering may have come from the first few $\mathrm{cm}$ of surface water. However, as $\theta_{\mathrm{v}}$ decreased towards nadir, the water volume contributing to the signal increased and reflectance increased (figure 8). With larger negative values of $\theta_{v}$, the reflectance dropped due to light attenuation by increased water absorption and scattering.

At low SSCs, the sensor may have detected some reflection at the water surface when $\theta_{v}$ was positive. For example, at $\theta_{v}=+10^{\circ}$ to $+20^{\circ}$ and $\psi=90^{\circ}$, the sensor probably detected the image of the tungsten-halogen lamp as the reflectance values increased suddenly (figure 8).

Figure 8 suggested that the viewing geometry per se had only a secondary influence on the reflectance/SSC relationship; the changes in reflectance due to SSC variations were for the most part of greater magnitude than those due to viewing geometry changes. Increasing sensor look angles away from nadir resulted in decreasing reflectance (up to 35 per cent) at high SSCs, in spite of a maximum reflectance shift towards low negative $\theta_{v}$, while at low SSCs, only small (1-4 per cent) increases in reflectance occurred away from nadir.

\subsection{Assessing the effect of viewing geometry on the reftectance/SSC relationship}

To assess the strength of the relationship between reflectance and SSC, correlations were performed for each combination of $\theta_{\mathrm{v}}$ and $\psi$ in each of the four wavebands (figure 9).

The changes in correlation coefficient $(r)$ with $\theta_{v}$ were not symmetric about nadir for either of the $\psi$ angles. In the visible bands, the values of $r$ fell as $\theta_{v}$ increased away from the light source. This is in conflict with the suggestion that for the remote sensing of water, off-nadir angles away from the light source are preferable to avoid Sun glitter (Austin 1974, Clarke and Ewing 1974). However, the hypothesis that the effect of viewing geometry on the reflectance/SSC relationship is wavelength-dependent was supported (figure 9). Similarities existed in the two visible bands centred at $0.55 \mu \mathrm{m}$ and $0.65 \mu \mathrm{m}$ but significant differences occurred for the other two bands. In the visible bands when $\psi=0$ the $r$ value dropped to $0.72-0.77$ for negative $\theta_{v}$ but high correlations of about 0.97 occurred for positive $\theta_{v}$. When $\psi=90^{\circ}$, the variation in $r$ values with $\theta_{v}$ increased. Other things being equal, $\theta_{v}$ had a slightly greater effect on $r$ values than did $\psi$.

In the near-infrared band $(0.75 \mu \mathrm{m})$ the opposite trend occurred as $r$ values decreased when $\theta_{v}$ increased towards the light source. High and constant correlations occurred for $\theta_{v}$ of $+10^{\circ}$ to $-30^{\circ}$ independent of $\psi$. Since the maximum irradiance of the halogen lamp used was around $0.7 \mu \mathrm{m}$, it is possible that lamp-glitter was excessive at positive $\theta_{v}$ in this band. Low and sometimes negative correlations 

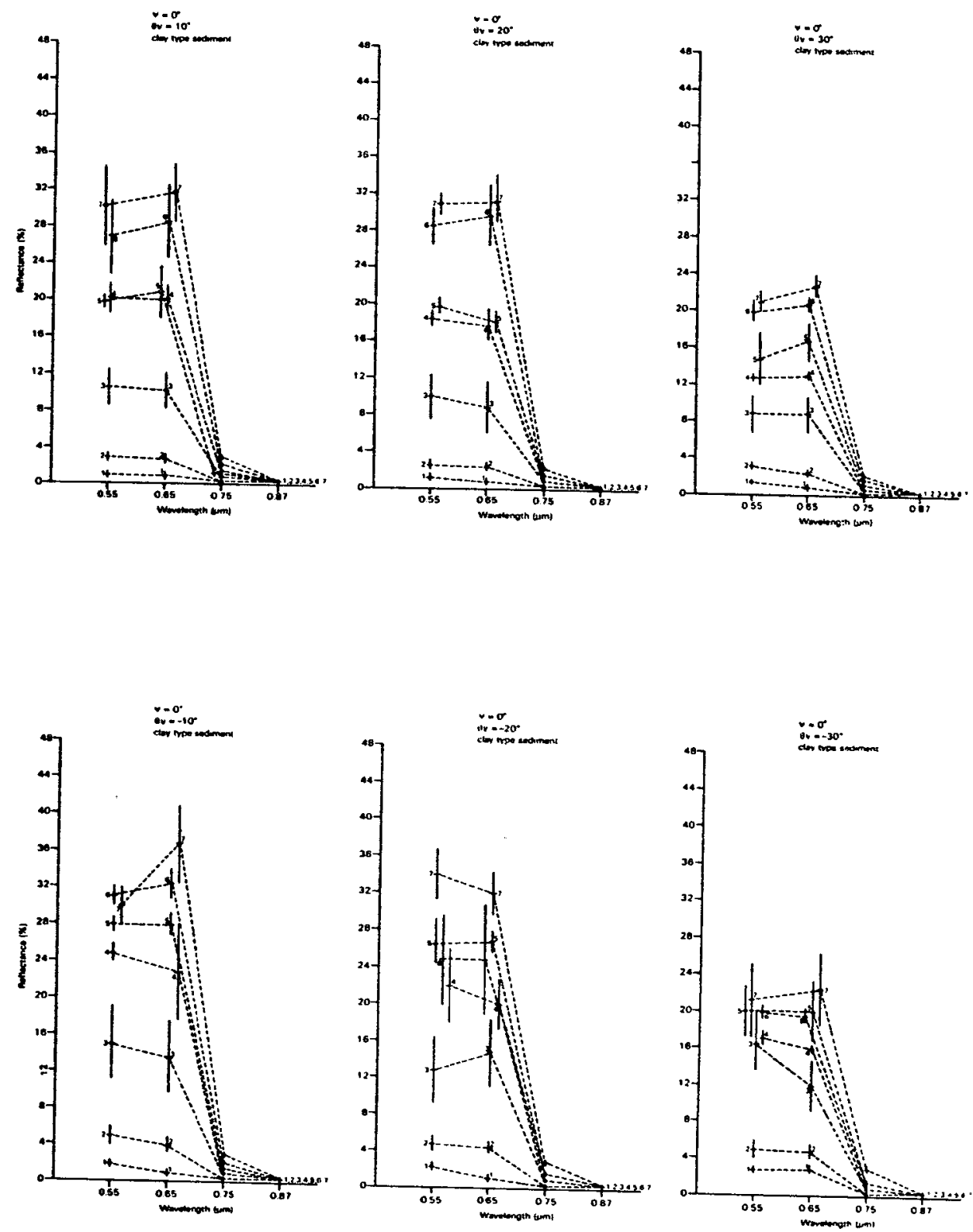

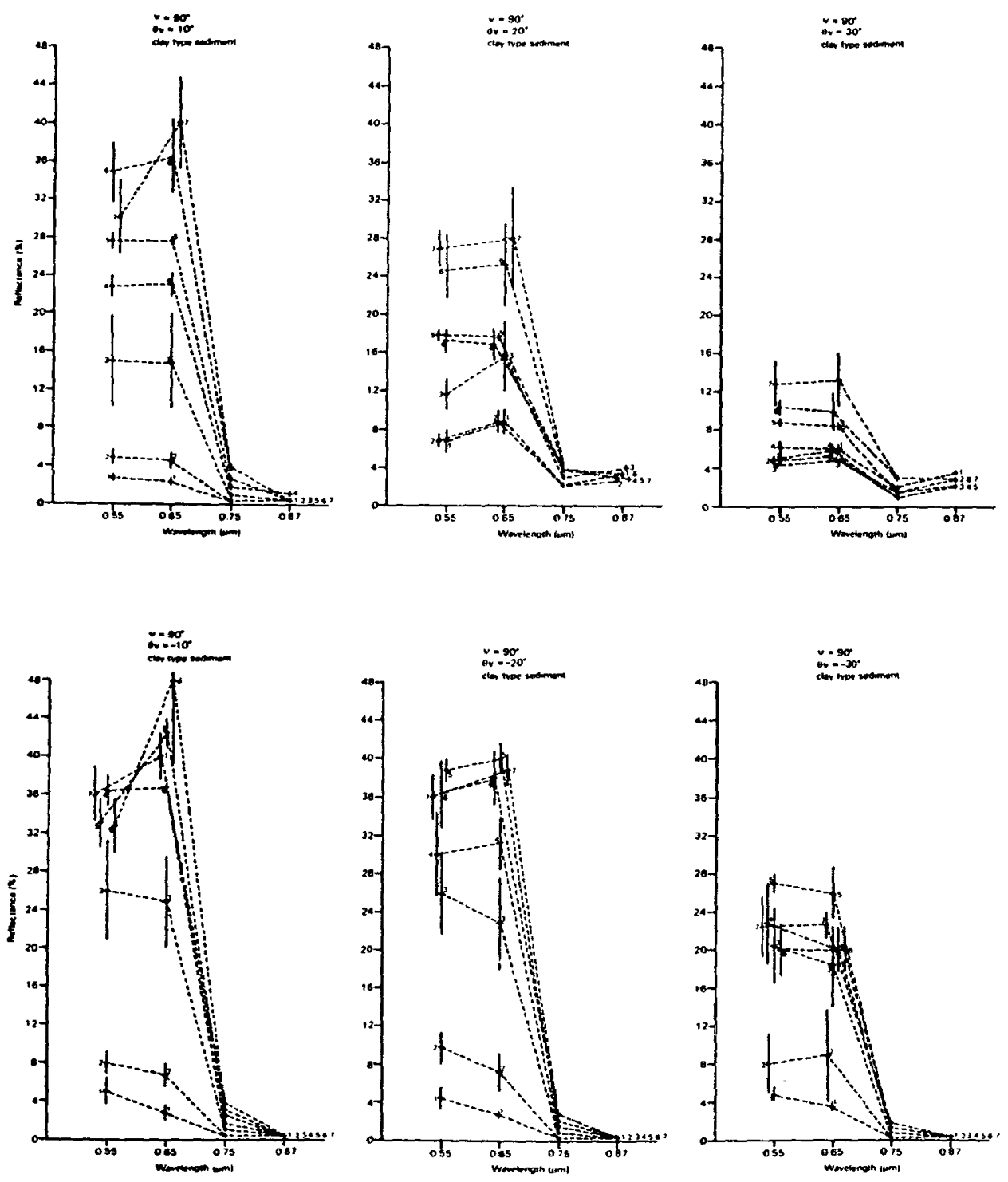

Figure 7. The effect of viewing geometry on the reflectance of SSC classes in different wavelengths. 

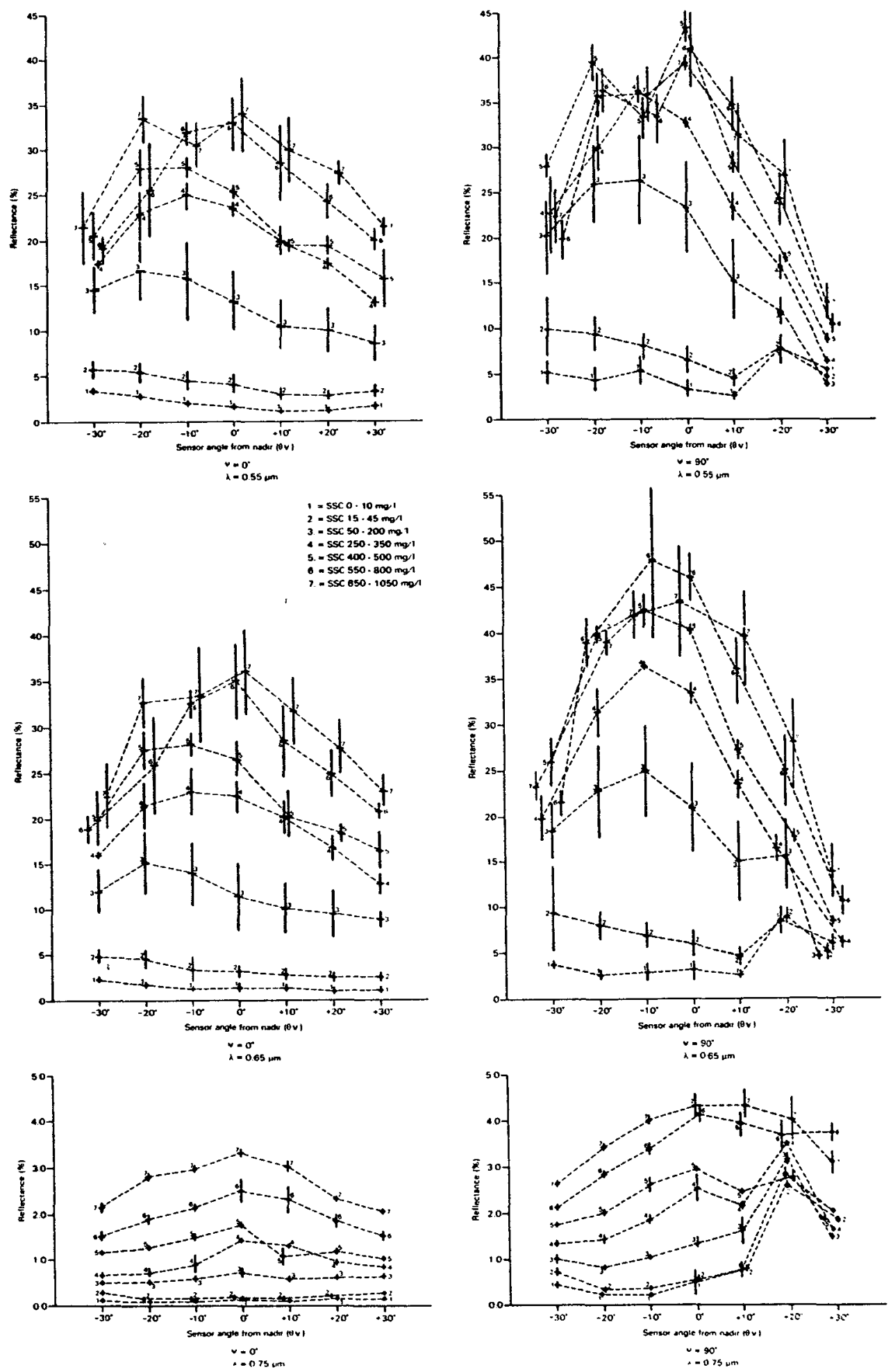

Figure 8. The eflect of look direction on the reflectance/SSC relationship. 
Viewing geometry and suspended sediment concentration

1369
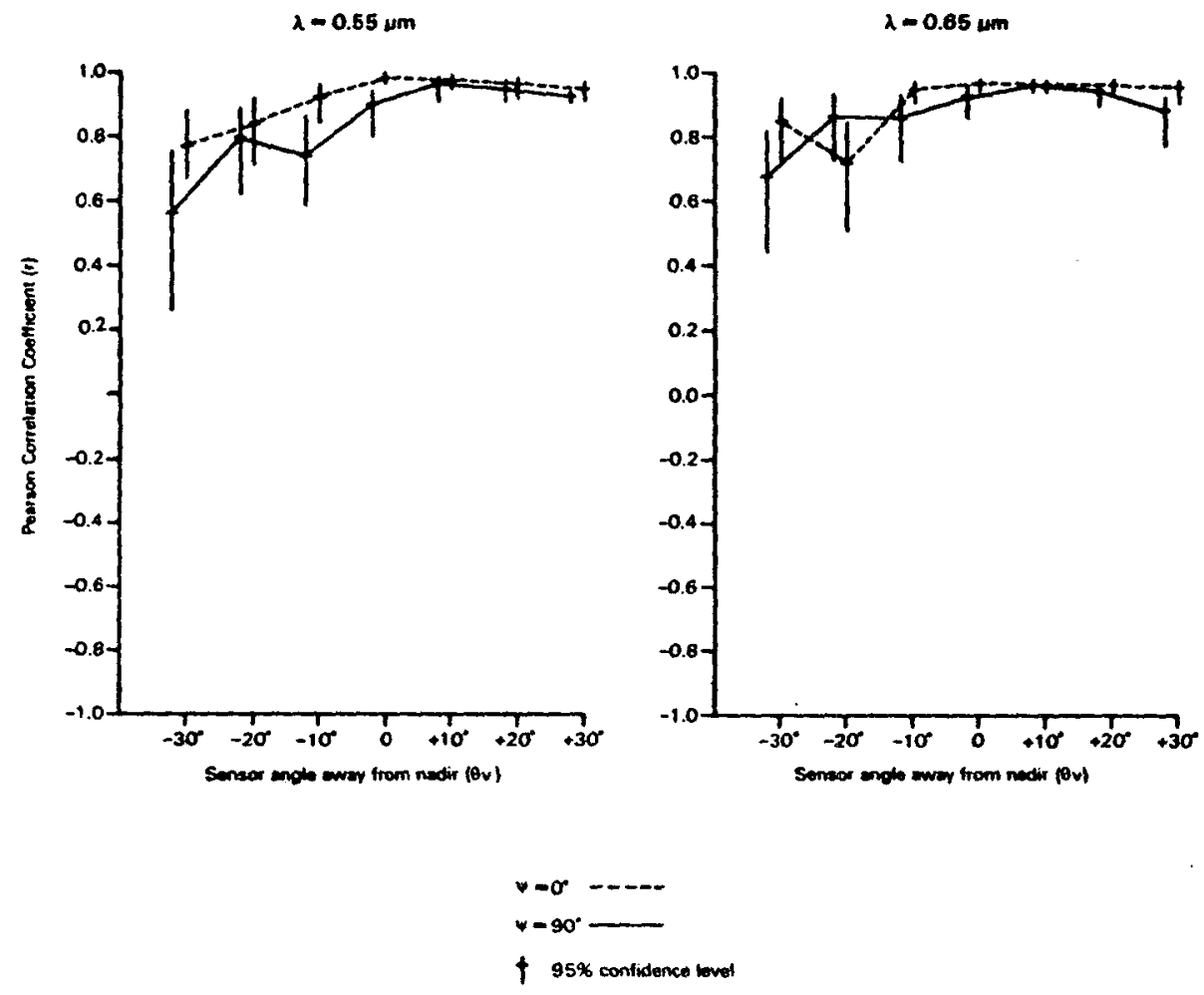

$\lambda=0.75 \mathrm{um}$

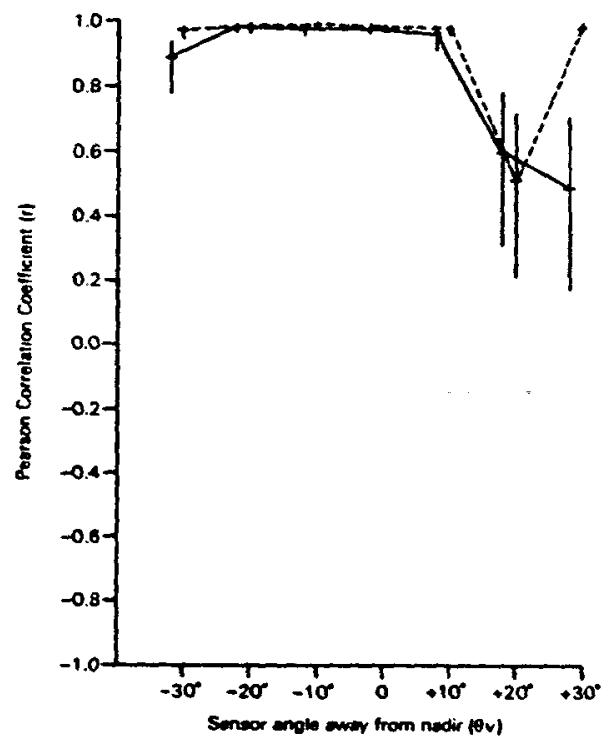

$\lambda=0.87 \mathrm{um}$

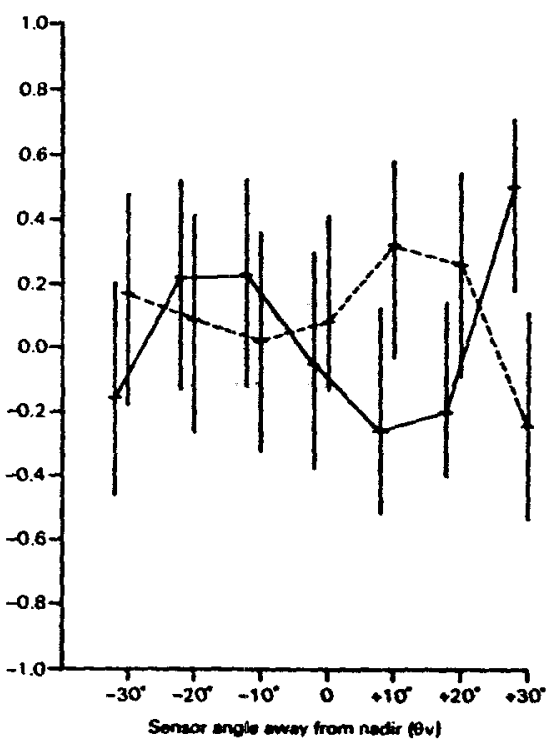

Figure 9. The strength of the reflectance/SSC relationship against viewing angle for different $\psi$ and wave bands. 
between reflectance and SSC occurred in the near-infrared band $(0.87 \mu \mathrm{m})$, the pattern of variation between $\psi=0^{\circ}$ and $\psi=90^{\circ}$ being statistically insignificant except for extreme off nadir angles.

Two explanations may be proposed for the unexpectedly small impact of viewing geometry on the correlation between reflectance and SSC. The first relates to figure 7 where it was shown that, irrespective of the combinations of $\theta_{v}$ and $\psi$, increases in SSC resulted in increases in reflectance. Reiterated in figure 8, viewing geometry appeared to be a secondary influence only. The second explanation is drawn from the geometry of the sensors $27^{\circ}$ field of view. This wide FOV caused overlap in the area seen by the sensor at adjacent $\theta_{v}$. For example, at $\theta_{v}=30^{\circ}$, the sensor 'sees' almost 70 per cent of the area 'seen' at $20^{\circ}$, and almost 45 per cent of the area 'seen' at $10^{\circ}$. The overlap effect leads to a reduction in the magnitude of changes in viewing geometry on the reflectance/SSC relationship.

\section{Summary and conclusions}

The primary aim of the work reported in this paper was to evaluate the effects of variation in viewing geometry on the relationship between reflectance and SSC. What emerged from the work is the utility of a laboratory experiment in isolating the factors that contribute to reflectance and thus permitting assessment of their significance. By gradually increasing SSCs a positive relationship between reflectance and SSC. particularly in the visible bands, was established in agreement with work elsewhere (Scherz et al. 1969, Scherz 1972, McCauley and Yarger 1976, Jerlov 1976, Holyer 1978, Alfoldi 1982). Variation in viewing geometry affects the sensitivity of reflectance to changes in SSC so that the asymplote of the reflectance/SSC relationship was reached at different points under different geometries. However, the effect of viewing geometry on the reflectance/SSC relationship appeared to be wavelength-dependent. Consistent increases in reflectance with SSC in the visible bands occurred but positive increases in $\theta_{\mathrm{v}}$ decreased the separability between SSC classes whilst maintaining the shift in maximum reflectance towards the longer wavelengths.

An increase in forward scattering with an increase in SSC was found in agreement with Jerlov (1976) and Preisendorfer (1976), yet the strength of the relationship between reflectance and SSC decreased for off-nadir view angles. This is inconsistent with established theory that suggests off-nadir viewing away from the light source to be preferable in the remote sensing of surface waters to avoid Sun glitter.

Several points emerge from the above that deserve more detailed attention. For instance, some wavelengths were more critically affected by changes in view geometry and a decrease occurred in the strength of the reflectance/SSC relationship for view angles away from the light source. The range and classes of SSC used may be another effect as might varying the colour, grain size and shape of the sediment suspension. The type of clay used here may only occur in specific environmental situations; use of a range of natural sediments of different colours and grain size distribution will undoubtedly yield results that can be applied better to real-world situations. Such a research programme is in hand. Future experiments could also focus on reduction of the effective FOV to less than $15^{\circ}$, on selecting view angles to eliminate the overlap effect and on simulation of surface waves. Only by isolating and varying all the elements of simulation for a range of conditions will models eventually emerge that are robust enough to cope with airborne or satellite remote sensing applications. 


\section{Acknowledgments}

The authors wish to acknowledge the award of an Instituto de Pesquisas Espaciais (INPE) Brazil/Fundacao de Amparo a Pesquisa do Estado de Sao Paulo (FAPESF) Postdoctoral Fellowship to EMMN and to thank Paul Bentley, Jill Ulmanis and Dr Liz Rollin of NERC for technical assistance. EMMN would also like to thank Professor S. Gregory and the University of Sheffield for the provision of study facilities in the Department of Geography.

\section{References}

ALFOLDI, T. T., 1982, Remote sensing for water quality monitoring. In Remote Sensing for Resource Management, edited by C. J. Johannsen and J. L. Sanders (Iowa: Soil Conservation Society of America), pp. 317-328.

Austin, R. W., 1974, The remote sensing of spectral radiance from below the ocean surface. In Optical Aspects of Oceanography, edited by N. G. Jerlov and E. S. Nielsen (New York: Academic Press), pp. 317-344.

BARtoluCCI, L. A., Robinson B. F., and SiLva, L. F., 1977, Fieid measurements of the spectral response of natural waters. Photogrammetric Engineering and Remote Sensing. 43, $535-598$.

Clarke, G. L., and Ewing, G. G., 1974, Remote spectroscopy of the sca for biological production studies. In Optical Aspects of Oceanography, edited by N. G. Jerlov and E. S. Nielsen (New York: Academic Press). pp. 389-413.

Conex, J. A., and Salzman, J. A., 1979, A comparison of measured and calculated upwelling radiance over water as a function of sensor altitude. Proceedings of the $13 \mathrm{th}$ International Symposium on Remote Sensing of Environment held in Ann Arbor, Michigan. (Ann Arbor: University of Michigan), pp. 1707-1720.

Curran, P. J., and Novo, E. M. M., 1988, The relationship between suspended sediment concentration and remotely sensed spectral radiance: a review. Journal of Coastal Research, 4, 351-368.

Curran, P. J., Hansom, J. D., Plummer, S. E., and Pleley, M. 1., 1987, Multispectral remote sensing of nearshore suspended sediments: a pilot study. International Journal of Remote Sensing . 8, 103-122.

HOLYER, R. J., 1978, T owards universal multispectral suspended sediment algorithms. Remote Sensing of Environment, 7, 323-338.

Jerlov, N. E., 1976, Marine Optics (Amsterdam: Elsevier).

KHORRAM, S., 1981, Water quality mapping from Landsat digital data. International Journal of Remote Sensing. 2, 145-154.

KIMES, D. S., SMITH, J. A., and RANSON, K. J., 1980, Vegetation reflectance measurements as a function of solar zenith angle. Dhotogrammetric Engineering and Remote Sensing, 46, 1563-1573.

Kollenkank, J. C., Vanderbilt, V. C., Daughtry, C. S. T., and Bauer, H. J., 1982, Canopy Reflectance as Influenced by Solar Illumination Angle, SR-PL-01038 (Washington, D.C.: NASA Scientific and Technical Information Facility).

KRIEBEL, K. T., 1978, Measured spectral bidirectional reflection properties of four vegetated surfaces. Applied Optics, 17, 253-258.

MacFARLANE, N., and Robinson, 1. S., 1984, Atmospheric correction of Landsat MSS data for a multidate suspended sediment algorithm. International Journal of Remote Sensing, 5 , $561-576$.

MCCLUNEY, W. R., 1976, Remote measurement of water colour. Remote Sensing of Environment, 5, 13-33.

MCCAuley, J. K., and YARGer, H. L., 1976. Kansas water quality using ERTS-1.In Remote Sensing of Earth Resources, edited by F. Shahrokhi (Tullahoma: University of Tennessee). pp. 521-541.

Mitron. E. J., 1980, A portable multiband radiometer for ground data collected in remote sensing. International Journal of Remote Sensing. 1, 153-165. 
Milton, E. J., and WEBB, J. P., 1987, Ground radiometry and airborne multispectral survey of bare soils. International Journal of Remote Sensing, 8, 3-17.

MOORF, J. K., 1977, Satellite surveillance of physical water quality characteristics. Proceedings of the 12th International Sympositum on Remote Sensing of Environment held in .Ann Arbor, Michigan, in 1977 (Ann Arbor: University of Michigan), pp. 445-462.

Preisendorfer, R. W., 1976, Hydrologic Optics (Honolulu. Hawaii: Joint Tsuami Experiment).

Ranson, K. J., Daughtry, C. S. T., Bizil, L. L., and Bauer, H. E., 1985, Sun-view angle effects on reflectance factors of corn canopies. Remote Sensing of Environment. 18, 142-161.

Rimmer, J. C., Collins, M. B., and Pattiaratchi, C. B., 1987, Mapping of water quality in coastal water using Airborne Thematic Mapper data. International Journal of Remotc Sensing. 8, 85-102.

RITCHIE, J., SCHIEBE, F., and MCHENRY, J. R., 1976, Remote sensing of suspended sediments in surface waters. Photogrammetric Engineering and Remote Sensing, 42, 1539-1575.

Scherz, J. P., GrafF, D. R., and BoYle, W. C., 1969, Photographic characteristics of water pollution. Photogrammetric Engineering, 35, 38-43.

SCherz, J. P., 1972, Remote sensing considerations for water quality monitoring. Procecdings of the 7th International Symposium on Remote Sensing of the Environment held in Ann Arbor, Michigan. in 1972 (Ann Arbor: University of Michigan), pp. 1071-1087.

Slater, P. N., 1980, Remote Sensing: Optics and Optical Systems (London: Addison Wesley).

WARDLEY, N. W., 1984, Vegetation index variability as a function of viewing geometry. International Journal of Remote Sensing, 5, 861-870.

Whitlock, C. H., Kuo, H. Y., and Le Cray, S. R., 1982, Criteria for the use of regression analysis for remote sensing of sediment and pollutants. Remote Sensing of Environment. 12, 151-168. 